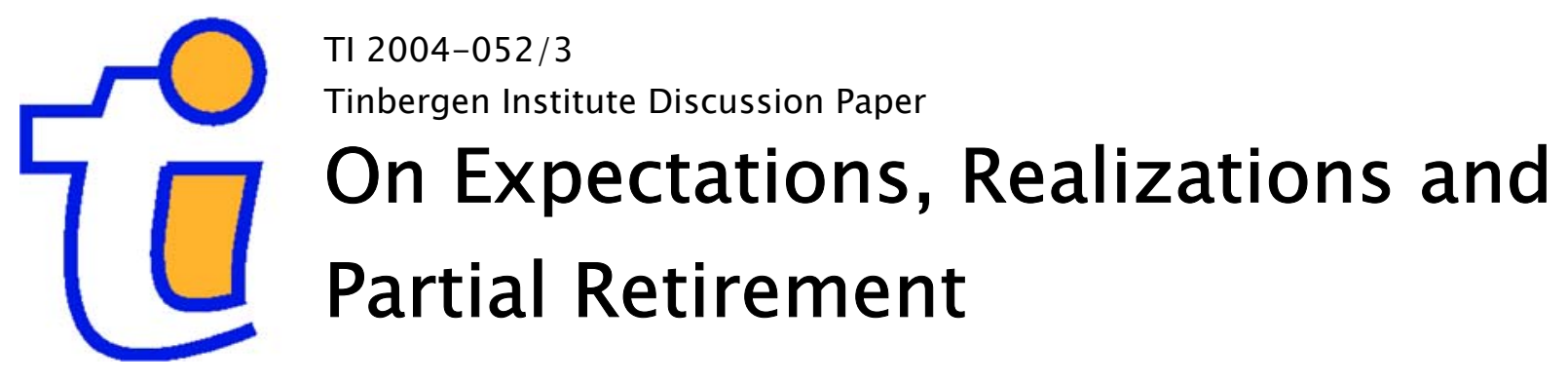

Mauro Mastrogiacomo

Faculty of Economics and Business Administration, Vrije Universiteit Amsterdam, Tinbergen Institute, and CPB Netherlands Bureau for Economic Policy Analysis. 


\section{Tinbergen Institute}

The Tinbergen Institute is the institute for economic research of the Erasmus Universiteit Rotterdam, Universiteit van Amsterdam, and Vrije Universiteit Amsterdam.

Tinbergen Institute Amsterdam

Roetersstraat 31

1018 WB Amsterdam

The Netherlands

Tel.: $\quad+31(0) 205513500$

Fax: $\quad+31(0) 205513555$

Tinbergen Institute Rotterdam

Burg. Oudlaan 50

3062 PA Rotterdam

The Netherlands

Tel.: $\quad+31(0) 104088900$

Fax: $\quad+31(0) 104089031$

Please send questions and/or remarks of nonscientific nature to driessen@tinbergen.nl.

Most TI discussion papers can be downloaded at http://www.tinbergen.nl. 


\title{
On Expectations, Realizations and Partial Retirement
}

\author{
Mauro Mastrogiacomo \\ Vrije Universiteit of Amsterdam and Tinbergen Institute.
}

December 2003

\begin{abstract}
This study investigates whether many people fear an unexpected shock in their financial situation around retirement and whether the related expectations and realizations match each other. We use the Dutch Social Economic Panel survey data, where expectations about the next year's financial situation are reported. We show that realized changes exceed expectations, and that this finding is more prominent around age 65. The descriptive statistics, as well as the nonparametric tests on the conditional distribution of expectations and realizations, suggest that individuals around retirement are overly pessimistic and attach more weight to prospective bad events than to good events. The model estimates show that their fears are unjustified, in particular when individuals are highly educated. Further the link between macro shocks, micro-shocks and expectations is investigated.
\end{abstract}

Key Words: retirement, expectations, non parametric test.

JEL Codes: D84, J26 


\section{Introduction}

According to the life-cycle model in its stripped-down form, people should dissave in the last phase of their life. This last phase begins at retirement, when individuals have already experienced a relevant (and anticipated) drop in income. If changes in income are fully anticipated, the stripped-down form of the life-cycle model predicts that consumption remains constant since it is always equal to individuals' average anticipated life-time resources ${ }^{1}$ Recent literature has shown that this model might fail to explain consumption behavior according to age. Banks, Blundell, and Tanner (1998) find that, around retirement, consumption tracks the drop in income. In addition, they also find that the drop in consumption is larger than the drop in income. Their findings are based on a test for the validity of a Euler equation for consumption on data from the British Family Expenditure Survey. Their forward-looking model predicts the evolution of consumption correctly during middle life and until about age 60. However, it fails to describe the post-retirement dip in consumption observed in the data. This makes empirical evidence difficult to reconcile with mainstream theory. Banks, Blundell, and Tanner (1998) examine a range of possible explanations. They exclude the possibility that this dip could be explained by liquidity constraints, since this should generate larger pre-retirement savings, which is at odds with the empirical evidence. For similar reasons, the authors also exclude the possibility of early retirement (ER) as an unexpected event, and that the solution of income uncertainty at retirement (associated with diminished current consumption) may cause the dip. They speculate that the occurrence of unexpected adverse information

\footnotetext{
${ }^{0}$ I thank Rob Alessie, Bas van der Klaauw and Maarten Lindeboom for commenting on previous versions of this study. I also thank the participants into the European Society of Population Economics annual meeting held at New York University from 13 to 15 of June 2003 and the participants into the conference on Improving Social Insurance Programs held at Maryland University from 13 to 15 of September 2003.

Part of this research was carried out at the Netherlands Bureau for Economic Policy Analysis (CPB).

${ }^{0}$ This paper is based on the Social Economic Panel (SEP) data administrated by Statistics Netherlands. The views expressed in this paper are of the author and do not necessarily reflect the views of Statistics Netherlands.

${ }^{1}$ That is, provided that there is no bequest; that individuals are rational; and that the other usual assumptions are satisfied (no uncertainty, separability of preferences, etc.). In general it is the marginal utility of consumption, and not consumption itself, that is to be smoothed across time periods.
} 
could have negatively influenced the consumption plans of consumers. Their data do not allow a test of this implication, and they leave open the question of whether the occurrence of unexpected shocks may have caused the dip in consumption $^{2}$.

This study starts from that point, and investigates whether many people fear an unexpected shock in their financial situation around retirement. We show that, in general, realized changes exceed expectations, and that this finding is more evident around age 65. This is done by using a household panel containing subjective information on expectations about the respondent's present expectations of household finances and the realized changes asked in the following year (see Section 2 below). The longitudinal nature of the data allows for direct comparison between the ex-ante question on expectations and the ex-post question on realizations. Sudden changes over time to family composition and the occurrence of labor-market-related shocks are also considered. In this way, we investigate the relationship between subjective expectations, realizations, and possibly unexpected events. The results will also question the validity of the rational expectations hypothesis used in most life-cycle models.

This analysis is relevant for a number of reasons. If the gap between expectations and realizations tracks retirement for some specific group, this could suggest new policies directed to affect pre-retirement savings. It could be interesting to identify what groups, if any, do not actually form rational expectations around retirement. Access to better information about how future retirees are treated may, for instance, influence the expectations of those who are currently still at work. In addition, since individuals are likely to save more during their working life this could provide new motivation to prolong elderly labor market participation. Further, since this study exploits Dutch data, the analysis will question the conventional wisdom that in the Netherlands policies should be addressed to increasing pre-retirementsavings. Supporters of this position use the argument that these increments are necessary because older individuals experience drops in income that are not foreseen, and therefore need to decumulate their wealth to finance consumption.

A difference between expectations and realizations is per se an indicator of

\footnotetext{
${ }^{2}$ Closely related to their study is that of Ameriks, Caplin, and Leahy (2002a). They also find that retirement affects expectations negatively, as will be shown later on in this study.
} 
inaccurate planning activity, or it is due to a shock that has not been foreseen. It does not support the assumption of anticipative behavior that is at the basis of the life-cycle model with expected utility. The comparison between the individual subjective distribution of expectations and the distribution of realizations will question, overall, the pertinence of the expected utility framework with rational expectations ${ }^{3}$. This is done in Appendix A following the methodology of Das, Dominitz, and van Soest (1999) and Das and van Soest (2001).

This study is not the first to investigate these issues. Using data from a new survey, Ameriks, Caplin, and Leahy (2002a) show that many working households do expect a considerable fall in consumption when they retire. Unfortunately, they only have a cross-section, and their respondents are only selected among highly-educated academics. They divide the sample into two groups: the currently-employed and the currently-retired. Those who are already retired report significantly smaller falls in consumption as compared with those falls expected by respondents who are still in work. They show that participation in the stock market plays a dominant role in explaining the gap between expectations and outcomes, indicating that much of the gap is a result of unexpected stock market appreciation. However, more recently, Hurd and Rohwedder (2003) have also analyzed a similar crosssection and report different results. They find that the predictions expressed by the future retirees do not differ from the realizations reported by the current retirees. But, because of the nature of their data, they cannot control for the future outcomes of those currently employed. While the studies of Ameriks, Caplin, and Leahy (2002a) and Hurd and Rohwedder (2003) look into expectations about consumption, this study looks at the other side of the story, namely expectations (and outcomes) of the retiree's financial situation which, among other things, could indicate expected dissaving to finance consumption around retirement. This study extends these studies by using a panel data set, and, by accounting for individual effects, tries to reconcile the conflicting evidence with standard theory. Our work generally supports the conclusions of Ameriks, Caplin, and Leahy (2002a), however, our results also support the view expressed by Hurd and Rohwedder (2003): that it is not the unanticipated inadequacy of resources that surprises individuals. The results

\footnotetext{
${ }^{3}$ A simple definition of rational expectations is that the individual subjective distribution expressed in the (categorized) expectations coincides with the observed distribution of the (categorized) realizations.
} 
attribute the gap between expectations and realizations to the occurrence of unexpected health-, family- or labor-market-related shocks and, especially, to the intrinsically overly pessimistic attitude of respondents.

Recently, some literature has focussed on the relation between expectations and realizations in retirement behavior. Gustman and Steinmeier (2001) find that individuals have a poor knowledge of their future pension benefit, even when they are about to retire. Individuals, who best know their own financial situation, can hardly state an expected pension benefit close to the one the authors compute using official pension formulas ${ }^{4}$. Contrary to the findings in this study, Gustman and Steinmeier (2001) do not find any systematic overestimation or underestimation of the underlying variable.

The study is organized as follows. Next, Section 2 describes the data and concepts. Section 3 shows the descriptive analysis with the main findings. First, there is a dip in expectations at age 64 that is not supported by realizations, second, there is a substantial distance between expectations and realizations around ER age. Section 4 presents the econometric model. Section 5 shows the results of the two models with two different dependent variables: expectations, in the first model; and the gap between expectations and realizations in the second. There the unjustified pessimism of respondents, especially if highly-educated, will be underlined. Section 6 will summarize the main results and conclusions. In addition, two Appendixes are included (A and B). Appendix A will follow the methodology of Das, Dominitz, and van Soest (1999), for the comparison of reported expectations and realizations. They refer to income data, while here wealth is considered. Their findings are supported here. The results of the non-parametric tests on predictions and realized changes (in that Appendix) suggest that individuals do not form rational expectations (in the sense explained above) around retirement. This means that their predictions are systematically inaccurate. This could depend on macro-shocks (as will be tested later on), but it is plausible to suspect that over the long period analyzed these will not point in the same direction. Appendix B will clarify the construction of the financial incentive variables.

\footnotetext{
${ }^{4}$ If individuals include other potential sources of income to finance their retirement into the expected retirement benefit (that are not directly dependent on their labor market performance), we think that some of the respondents predicting failures could be explained.
} 


\section{Data and concepts}

This study tries to test whether expectations around retirement deteriorate, and whether their evolution is mirrored in reported realizations. This study does not present consumption in the analysis (which is not observed in the data), but looks directly at the expectations of the financial situation as the dependent variable, as well as the realizations of these expectations one period ahead.

Expectations are observed in the Social Economic Panel Data (SEP). It is administered by Statistics Netherlands (CBS), and contains approximately 5000 households per year. In structure and contents, this panel survey is similar to the German Social Economic Panel (GSOEP) and the American PSID. The aim of the SEP is to provide a description of the most important elements of individual and household welfare, and to monitor changes in these elements over time ${ }^{5}$.

The sample includes non-self-employed respondents aged 50 to 70 who have been in the survey in the period 1987 to 1998 for at least 3 years ${ }^{6}$. The sample consists of approximately 8000 observations. This amounts to 2623 individuals participating from 3 to 8 times into the survey. Two other samples are used. The first is the repeated cross-section with 17,093 observations in the period 1990 to 1998, which is used for the income analysis ${ }^{7}$. The second is the two-year (partially) rotating panel with about 10,000 observations. This is used in the non-parametric tests in Appendix $\mathrm{A}^{8}$.

In the SEP, the questions eliciting subjective expectations and realizations refer both to individual income and to household financial situation.

\footnotetext{
${ }^{5}$ This survey is not specifically designed to cover retirement issues per se. The SEP is representative of the Dutch population, but it excludes individuals living in special institutions such as nursing homes. Statistics Netherlands applies a two-stage sampling procedure. Firstly, municipalities are drawn with probability depending on the number of inhabitants (big cities are drawn with certainty). Next, addresses are selected randomly. All households present at the selected address are interviewed, up to a maximum of 3 households. Over the years 1984 to 1989, households were interviewed twice a year. Since 1990 the survey has been held annually.

${ }^{6}$ The self-employed are dropped because of the impossibility to compute their future pension benefits. The 3-year panel is necessary because of the lag of the income questions, which refer to earnings in the previous year.

${ }^{7}$ Income is registered in the SEP differently across the 1980s and the 1990s, and therefore the income analysis only includes the waves available for the 1990s.

${ }^{8}$ The tests are based on the comparisons between two periods only and do not need the 3-year panel.
} 
The answers to these questions are highly correlated ${ }^{9}$. Therefore, 'household financial situation' is used which is repeated in all waves of the panel. Hence, the question about expectations is: "How do you think the financial situation of your household will develop in the next 12 months?". It is answered by choosing one of the five ordered categories listed from 1 to 5: "significantly worsen", "somewhat worsen", "remain the same", "somewhat improve", "significantly improve" ${ }^{10}$. The question about realizations has the same five ordered categories as possible answers and is formulated as follows: "How did your financial situation develop in the last 12 months?". The answers to these two questions will be directly compared in Appendix A, in order to question whether individuals form predictions that systematically match realizations ${ }^{11}$.

The covariates that may have an influence on these two subjective responses are: time effects; taste shifters; retirement dummies; shocks; and financial indicators.

Time effects will control for macro-shocks common to all individuals over time. Taste shifters will include the usual exogenous regressors, like education and family size.

Early retirement dummies will detect the exact timing of retirement. In order to identify the potential early retirees, different definitions of (partial) retirement are used. This is necessary since there is no clear cut definition of ER in the survey. In any of these definitions retirement is identified by a transition to the current state. This means that respondents who retire in the year of observation (year $t$ ) are identified. Any definition used does not explicitly refer to complete retirement. This is due to the registration in the SEP of the labor participation status. This question refers to the main activity of the respondent, and those answering that 'work is not their main activity' do keep a residual participation on the labor market. As a first definition, the labor participation question is an excellent tool to identify

\footnotetext{
${ }^{9} 75 \%$ of the respondents report exactly the same answer to both questions while $22 \%$ report an adjacent category (computations available on request). This indicates either that individuals report the same concept while answering both questions, or that they have difficulties in separating the two concepts.

10 "Don't know" answers are accepted but not used in this analysis.

${ }^{11}$ The answers to questions concerning expectations are not easy to interpret. This because individuals are asked to report point expectations. Previous literature has argued that individuals will not necessarily make a prediction that corresponds to a mathematical "expectation". This is tested more extensively in Appendix A.
} 
(partial) retirement. Then, using the amount of weekly working hours allows a second definition of partial retirement as the status of those individuals for whom participation drops at least by $25 \%$ of the working schedule relative to the panel observation in $t-1$. In addition a third income dependent definition of partial retirement is used. Looking at income sources, an individual is defined as 'retiring in panel wave $t$ if he or she declares in $t+1$ an income for period $t$ that is composed of $50 \%$ of retirement income, provided that the individual was working in period $t-1$ '. A fourth definition will mark the shift into old age pension (Algemene ouderdomswet - AOW). Unlike the previous definitions, this is straightforward to identify, since individuals get into such program 'when they turn 65'.

A variable for labor market-related "shocks" is derived from a question asked to those who stopped working within the last year. The question is: "Why did you stop working?". A range of 12 possible answers is given, and in this study the ones that are used are: illness of the respondent; illness of the partner or another family member; respondent was fired; company bankrupts. Changes in the family composition will also be included. It is difficult to asses how unanticipated these changes are.

Among the financial indicators, we introduce the future income profile of the individual (including both labor income and expected pension stream till age 70). This is summarized in the "present discounted value" term. This variable will be introduced in the estimation to test whether individuals expecting higher future earnings, or a more generous pension treatment, form higher expectations over the next year. Appendix B provides some details about the construction of this variable ${ }^{12}$. Finally, in the descriptive analysis and in Appendix A wealth is used as a financial indicator. The money measure of financial situation (that is the object of the subjective questions quoted above) is derived from wealth data. It tries to approximate the concept of "liquid wealth". It sums up savings account, savings certificates, bonds, mortgage bonds, stocks, options, other savings, money loans, current account; and subtracts loan, credit, other loans, other debts, negative balance checking account. For more detailed information about wealth data in

\footnotetext{
${ }^{12}$ Indeed, some information relative for ER age and ER replacement rates is missing from the SEP, but is essential for the computation of this variable. This issue will be addressed using an auxiliary data set, the CERRA (Center for Research on Retirement and Aging) that allows the imputation of the future age of eligibility for ER. This will be implemented in the PDV formula that will include all life-cycle earnings of the individual, as specified in Appendix B.
} 
the SEP, see Alessie and Kapteyn (2001).

\section{Descriptive Analysis}

Figure 1 shows that individuals between age 60 and 65 experience an income drop, as the life-cycle model predicts.

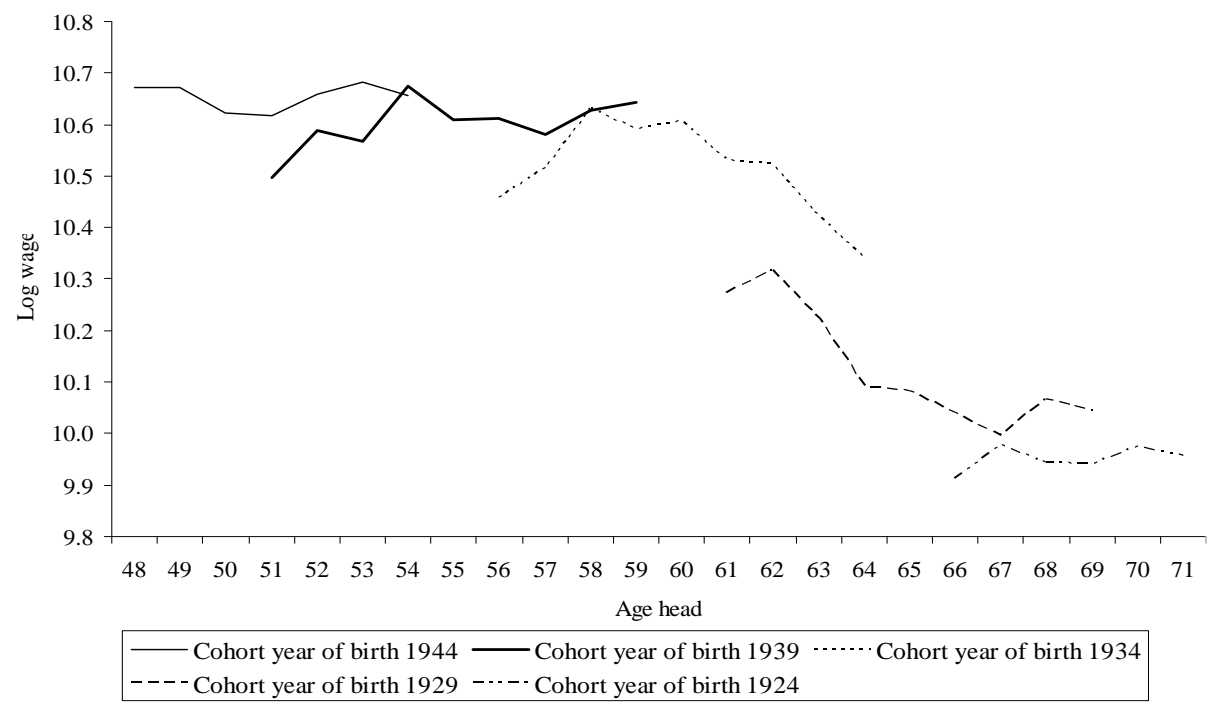

Figure 1: Male and Female total log-income by age and cohort, period 1990-1998. Explanatory note: Log-income drop around (early) retirement age. This table is based on repeated cross-sections in order to increase the dimension of the sample. Observations $=17,093$.

Source: SEP, own computations.

The figure plots different cohorts over time (the average year of birth is given). For the two cohorts in which respondents are around ER age (60), an income drop is observed. The vertical distance among the segments indicates that younger cohorts have higher earnings when they reach a given age.

Following Table 1 "liquid wealth" returns results that are consistent with qualitative realizations ${ }^{13}$. This shows that this wealth measure is consistent

\footnotetext{
${ }^{13}$ Equality should give a result close to zero but here it is not the case. In addition we
} 
Table 1: Financial situation and realizations

\begin{tabular}{lccr}
\hline Realized category (c) & $\begin{array}{c}\text { Value corresponding } \\
\text { to the category }\end{array}$ & $\begin{array}{c}\text { Delta liquid } \\
\text { wealth }\end{array}$ & Observations \\
\hline Big increase & 5 & 28411 & 179 \\
Increase & 4 & 5507 & 1005 \\
Equal & 3 & 774 & 5002 \\
Decrease & 2 & -700 & 1384 \\
Big decrease & 1 & 273 & 469 \\
Missing & & 1856 & 365 \\
& & & \\
Observations & & & 8404 \\
\hline
\end{tabular}

Explanatory note: Respondents are selected when participating for 3 consecutive years in the survey. Delta of liquid wealth between adjacent years are reported in Dutch guilders (f). 1 euro $=$ f 2.2. Base year 1990. Panel period 1984-1998.

Source: SEP, own computations.

with the subjective question about the realization of household financial situation. Indeed individuals could also have different concepts in mind of what is meant by 'financial situation'.

Figure 2 plots the main finding of this analysis: the evolution of expectations and realizations over age. The only evident drop in expectations occurs at age 64, when individuals are about to qualify for the AOW (at age 65). Around the age of ER, the distance between expectations and realizations also increases.

The overall picture that we derive is that, in general, realizations are better than expectations, and that this is definitely the case around the entitlement to the AOW. Furthermore, expectations are generally always below 3, i.e. the value indicating "no change", and these are also declining over age. This is not in line, at least in principle, with the already quoted finding of Banks, Blundell, and Tanner (1998) that estimating consumption with a forward-looking model overestimate realized consumption. They point indeed to an optimistic functioning of expectations. Our finding is, however,

cannot attach much significance to the first and the last category. It is worth noting that the question asked in the SEP refers to the financial situation of the household. Liquid wealth is a relevant component of what the question refers to. The figures are reported in Dutch guilders and refer to the wealth increments between two adjacent years. 


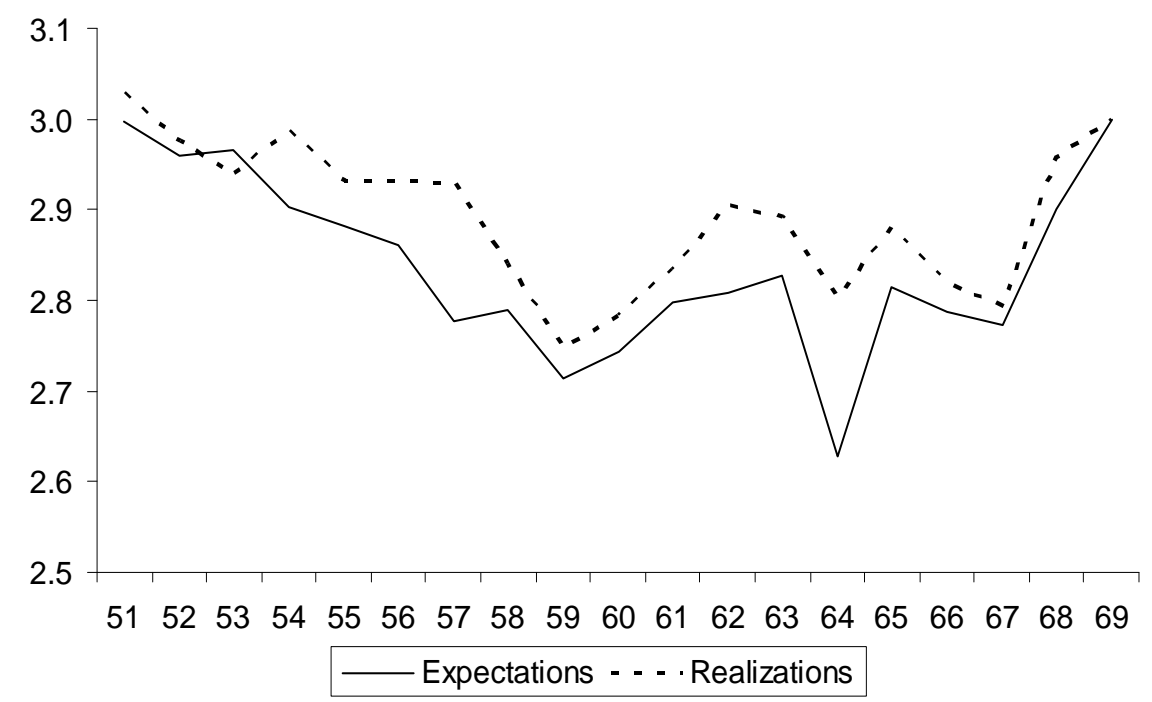

Figure 2: Expectations and realizations of household finances according to age. Explanatory note: This figure is based on the 3-year panel. There are 8404 observations for the expectations in $t$-1, and 8039 for the realizations in $t$. Expectations and realizations are increasingly ordered 1 to 5 .

Source: SEP, own computations 
in line with Das, Dominitz, and van Soest (1999), and Ameriks, Caplin, and Leahy $(2002 a)^{14}$.

Figure 3 plots expectations over the period 1987-1998. These seem to have become more positive over time, though these remain in a small neighborhood of variation. Interesting is the pattern around the economic slowdown in 1991-1993 . Increasing expectations follow the positive business cycle pattern of the second half of the 1990s. Whether macro-shocks do play a role or not in the analysis will be dealt with in the estimation. However, it is plausible to suspect that, given the ten-year-long panel employed, macro-shocks should not affect expectations or realizations only in one direction.

Table 2 shows the distribution of expectations for different groups of respondents. It shows that the population of non-retirees ${ }^{15}$ is less pessimistic than those partially retiring or entering social security. The sum of those expecting a decrease or a big decrease of their finances is about $21 \%$ for the non-retirees, while it is from $13 \%$ to $20 \%$ larger for the retiring individuals. This indicates again that not only around age 65 , but also around ER, expectations are lower.

Table 3 shows the frequency of realizations in $t$, given expectations in $t-1$. If individuals were fully rational predictors, we should observe the bold diagonal of this table with figures close to $100 \%$. It is indeed not the case. Accurate forecasts are only done by individuals expecting no change in their finances (largest group), while we see that improvements occur also for those who did not expect it. The percentages show that individuals may be overly pessimistic almost as much as too optimistic. Nevertheless, a vast majority of respondents do expect a drop in their finances, while a minority expects an increase. This means that the marginal distribution of the outcomes again indicates the pessimism of the respondents.

In the remainder of the study, we will investigate in more detail the evolution of expectations and the gap with realizations. Further analysis is necessary to assess whether, ceteris paribus, there is a relation between these two dependent variables and the covariates introduced in the previous

\footnotetext{
${ }^{14}$ In Appendix A, this result will be considered more in detail, by directly comparing expectations and realizations. The distributions of the two variables will be compared. This makes it possible to perform non-parametric tests that investigate which location of the individual subjective distribution, if any, is reported when answering the question about expectations.

${ }^{15}$ Those who are not retiring according to any retirement definition.
} 


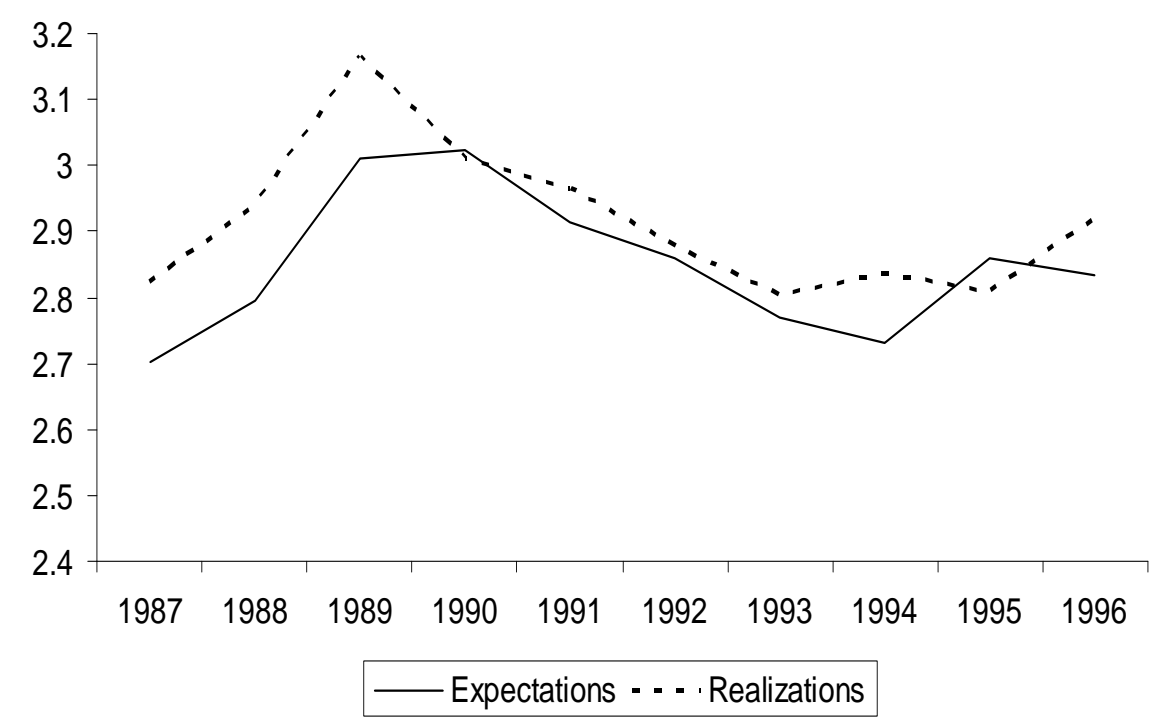

Figure 3: Expectations and realizations over time.

Explanatory note: This figure is based on the 3-year panel. There are 8404 observations for the expectations in $t$-1, and 8039 for the realizations in $t$. Expectations and realizations are increasingly ordered 1 to 5 .

Source: SEP, own computations 
Table 2: Future expectations of household finances around retirement: different definitions

\begin{tabular}{lccccc}
\hline $\begin{array}{c}\text { Expected } \\
\text { category }\end{array}$ & $\begin{array}{c}\text { Self-reported } \\
\text { definition }\end{array}$ & $\begin{array}{c}\text { Working } \\
\text { hours }\end{array}$ & $\begin{array}{c}\text { Income } \\
\text { definition }\end{array}$ & $\begin{array}{c}\text { Old age } \\
\text { pensioners }\end{array}$ & $\begin{array}{c}\text { Non- } \\
\text { retirees }\end{array}$ \\
\hline Big increase & $0.3 \%$ & - & - & $1.2 \%$ & $0.7 \%$ \\
Increase & $8.8 \%$ & $9.9 \%$ & $4.1 \%$ & $8.9 \%$ & $8.6 \%$ \\
Equal & $50.4 \%$ & $55.0 \%$ & $54.2 \%$ & $52.2 \%$ & $69.3 \%$ \\
Decrease & $30.7 \%$ & $27.6 \%$ & $33.7 \%$ & $26.8 \%$ & $18.3 \%$ \\
Big decrease & $9.8 \%$ & $7.5 \%$ & $8.0 \%$ & $10.9 \%$ & $3.2 \%$ \\
Observations & 387 & 373 & 389 & 496 & 7208 \\
\hline
\end{tabular}

Explanatory note: The table is based on the 3-year panel. The total number of observations is 8404 . However, some individuals become retired according to more than one definition. Therefore, the number of observations in this table is larger than the total. Non-retirees are those individuals who do not qualify for any of the four retirement definitions considered in the table.

Source: SEP, own computations. 
Table 3: Expectations and realizations at the individual level

\begin{tabular}{lcccccr}
\hline $\begin{array}{c}\text { Realization financial } \\
\text { situation in } t\end{array}$ & Big increase & Increase & Equal & Decrease & Big decrease & 0bs \\
\hline & & & & & & \\
Big increase & $19 \%$ & $8 \%$ & $2 \%$ & $2 \%$ & $1 \%$ & 179 \\
Increase & $38 \%$ & $33 \%$ & $11 \%$ & $8 \%$ & $7 \%$ & 1,005 \\
Equal & $33 \%$ & $45 \%$ & $70 \%$ & $51 \%$ & $33 \%$ & 5,002 \\
Decrease & $4 \%$ & $11 \%$ & $14 \%$ & $31 \%$ & $24 \%$ & 1,384 \\
Big decrease & $6 \%$ & $4 \%$ & $3 \%$ & $9 \%$ & $35 \%$ & 469 \\
& & & & & & \\
Observations & 52 & 661 & 5,423 & 1,580 & 323 & 8039 \\
\hline
\end{tabular}

Explanatory note: The table is based on the 3-year panel. The total number of observations is 8404 . Realizations have 365 missing values. The table compares the matching, at the individual level, between expectations in $t-1$ and realizations in $t$.

Source SEP: own computations. 
section.

\section{Econometric model}

In the models, $y_{i, t}$ denotes in turn the categorized answer to the question about expectations and the difference between expectations and realizations ${ }^{16}$. As in a standard ordered response model, the dependent variable is related to the underlying latent variable $y_{i, t}^{*}$ in the following way:

$$
y_{i, t}=j \quad \text { if } \quad\left(m_{j-1}<y_{i, t}^{*} \leq m_{j}\right) \quad j=1, \ldots, 5 .
$$

The boundaries $-\infty=m_{0}<m_{1}<\ldots<m_{4}<m_{5}=\infty$ are constant across individuals and will be estimated.

The underlying latent variable is modeled by the equation:

$$
y_{i, t}^{*}=\beta_{0}^{\prime} x_{i, t}+\lambda_{t}+\tilde{\alpha}_{i}+u_{i, t} \quad \mathrm{i}=1, \ldots, \mathrm{N}, \mathrm{t}=1, \ldots, \mathrm{T},
$$

where $x_{i, t}$ is a vector of taste shifters reflecting, for example, education, gender and family composition. Time effects $\lambda_{t}$ are included to allow for macro-shocks, common to all respondents and not varying with $x_{i, t}$. The parameter $\tilde{\alpha}_{i}$ is an individual specific (random) effect indicating unobserved heterogeneity across individuals.

The white noise, which is the individual time-specific error term $u_{i, t}$, is normally distributed and independent of the regressors $x_{i, t}$ and of the individual effect $\tilde{\alpha}_{i}$. The latter is treated as a random effect. We allow for an underlying correlation in Mundlak form. This means that the relation between $\tilde{\alpha}_{i}$ and $x_{i, t}$ is specified as $\tilde{\alpha}_{i}=\alpha_{i}+\beta_{1}^{\prime} \bar{x}_{i}$. In $\bar{x}_{i}$ only those variables expected to be correlated with $\tilde{\alpha}_{i}$ are included.

\footnotetext{
${ }^{16}$ Expectations are ordered from 1 to 5 , where 1 is very poor and 5 very good. The dependent variable in the second model is expectations in $t-1$ minus realizations in $t$ of household financial situation. The original 9 possible categories (from -4 to 4 , including zero) have been reduced to 5 by grouping the values $-4,-3,-2$ and $2,3,4$. The variable is then re-coded from 1 to 5 , where 1 stands for "expectations a lot lower than realizations "; 2 stands for "expectations somewhat lower than realizations"; 3 stands for "expectations equal to realizations "; 4 stands for "expectations somewhat higher than realizations "; and 5 stands for "expectations a lot higher than realizations". This means that the higher the dependent variable, the more unjustifiably optimistic the respondent.
} 


\section{Results}

The results are shown in Table 4. Four models are described. The first two occupy the left panel of the table, and have expectations in $t$ as the dependent variable. In the left panel, the first model (Model 1) does not include the interactions between eligibility for mandatory retirement and education. The second model (Model 2), does.

The last two models of Table 4 occupy the right panel of the table which shows results for Model 3 and Model 4. In the right panel, the dependent variable is the gap between expectations in $t-1$ and realizations in $t$ and Model 3 also does not include the interactions between eligibility for mandatory retirement and education.

\subsection{Expectations model}

This section describes the left panel of table 4, which comprises the first four columns of estimates and t-values. It refers to the model with categorized expectations in $t$ as the dependent variable. Evidently, for this table we had to shift from the analysis of the expectations in $t-1$, carried out so far, to expectations in $t$, since we can identify shocks only between years $t-1$ and $t^{17}$. In addition, most comments on the model results will not specify whether we refer to Model 1 and Model 2 in the left panel since these are virtually identical, with the exception of the results concerning eligibility for mandatory retirement.

The first interesting result concerns the time effects. Here the hypothesis of absence of macro shocks is rejected. The time effects are, jointly, significantly different from zero, with a $\chi_{9 ; 0.05}^{2}=80.79$ (far exceeding the critical value of 16$)$. The time coefficients are neither always positive nor always negative. This means that, over time, macro effects did not affect expectations in one direction only.

The coefficients for the taste shifters are generally significant. Males report lower expectations than females. Highly-educated individuals have higher expectations relative to elementary-educated respondents (who are the

\footnotetext{
${ }^{17}$ We want shocks to precede the reporting of expectations. However, the pattern of this variable according to age is identical to the one in Figure 2. Some attrition is present between waves $t-1$ and $t$. This accounts for the different amount of observations. We return to expectations in $t-1$ in the remainder of Table 4.
} 
reference case). The educational dummies are assumed to be uncorrelated to the individual effect (for older individuals these are constant over time).

The coefficients for the timing of individual retirement are all negative. This was expected since the main findings of the descriptive analysis had shown dips in expectations associated to the time of ER and AOW. Of this set of indicators, only those which capture the occurrence of the old age pension are significantly different from zero. This points to the notion that around mandatory retirement, when an income drop is evident, individuals have lower expectations about the future developments of their financial situation. This reinforces the empirical findings in Section 3, in the sense that it establishes a systematic relation, ceteris paribus, between mandatory retirement and the evolution of expectations. The model results also indicate what groups, around retirement, become more pessimistic. Among the dummies that identify mandatory retirement for the different education levels, the reference group is 'mandatory retirement for elementary education'. The higher education levels alone indicate a positive relation to expectations. This is no longer the case when education interacts with the indicator for individuals turning 65 (Model 2). Higher-educated respondents have lower expectations when they become eligible for AOW. This is in line with the results of other studies (Ameriks, Caplin, and Leahy 2002a).

The coefficient associated with labor market "shocks" is, as expected, negative and significant. It indicates that those experiencing events such as their employer becoming bankrupt, or a health shock that prevents them from working, have lower expectations about the future. All the changes in family composition and marital status that are listed do not turn out to be significant. For these kind of changes, it is more questionable to assume that they were completely unexpected.

The first difference of the present discounted value of future earnings and benefits up to age 70 (over $10^{5}$ guilders) is introduced among the financial indicators. A positive sign is expected. This because individuals with a more generous pension treatment or with high expected future income, should report more positive expectations. The coefficient is significant and indicates that people expecting higher future earnings have, ceteris paribus, higher expectations. This indicates that long-run implications affect the short-run prediction implied by the question concerning expectations. The variance of the individual effect is not significant. However, endogenous individual effects arise when looking at some exogenous characteristics, such as family size. This is a plausible result: the individual effect picks up some time- 
Table 4: Multivariate analysis

\begin{tabular}{|c|c|c|c|c|c|c|c|c|}
\hline \multirow{2}{*}{$\begin{array}{c}\text { Ordered Probit Estimates } \\
\text { Time effects }\end{array}$} & \multicolumn{2}{|c|}{$\begin{array}{c}\text { Expectations } \\
\text { in } t \\
(\operatorname{model} 1)\end{array}$} & \multicolumn{2}{|c|}{$\begin{array}{c}\text { Expectations } \\
\text { in } t \\
(\operatorname{model} 2)\end{array}$} & \multicolumn{2}{|c|}{$\begin{array}{c}\text { Difference } \\
\text { Expectations } \\
\text { in } t-1 \text { and } \\
\text { realizations in } \\
t \text { (model } 3) \\
\end{array}$} & \multicolumn{2}{|c|}{$\begin{array}{c}\text { Difference } \\
\text { Expectations } \\
\text { in } t-1 \text { and } \\
\text { realizations in } \\
t(\text { model } 4)\end{array}$} \\
\hline & Estim & t-val & Estim & $\mathrm{t}$-val & Estim & $\mathrm{t}$-val & Estim & t-val \\
\hline Year $t$ is 1988 & -0.08 & -1.56 & -0.08 & -1.50 & -0.02 & -0.40 & -0.02 & -0.44 \\
\hline Year $\mathrm{t}$ is 1989 & 0.19 & 3.33 & 0.19 & 3.30 & -0.07 & -1.42 & -0.08 & -1.45 \\
\hline Year $\mathrm{t}$ is 1990 & 0.03 & 0.39 & 0.02 & 0.23 & -0.06 & -0.86 & -0.06 & -0.91 \\
\hline Year $\mathrm{t}$ is 1991 & -0.02 & -0.31 & -0.03 & -0.40 & 0.14 & 1.98 & 0.14 & 1.94 \\
\hline Year $\mathrm{t}$ is 1992 & 0.02 & 0.29 & 0.01 & 0.18 & 0.05 & 0.74 & 0.04 & 0.63 \\
\hline Year $t$ is 1993 & -0.23 & -4.32 & -0.24 & -4.39 & 0.13 & 2.52 & 0.13 & 2.48 \\
\hline Year $t$ is 1994 & -0.28 & -5.11 & -0.28 & -5.10 & 0.10 & 2.00 & 0.10 & 1.99 \\
\hline Year $\mathrm{t}$ is 1995 & -0.07 & -1.49 & -0.07 & -1.51 & 0.00 & -0.07 & -0.01 & -0.15 \\
\hline $\begin{array}{l}\text { Year } \mathrm{t} \text { is } 1996 \\
\text { Taste shifters }\end{array}$ & -0.13 & -2.84 & -0.13 & -2.83 & 0.20 & 4.73 & 0.20 & 4.73 \\
\hline Males & -0.06 & -2.07 & -0.06 & -2.11 & 0.02 & 0.60 & 0.02 & 0.57 \\
\hline Family size & -0.07 & -1.40 & -0.07 & -1.39 & -0.11 & -2.39 & -0.11 & -2.46 \\
\hline Lower vocational education & 0.09 & 2.39 & 0.09 & 2.21 & -0.04 & -1.00 & -0.03 & -0.75 \\
\hline Intermediate vocational education & 0.11 & 3.15 & 0.14 & 3.87 & 0.01 & 0.19 & 0.03 & 1.01 \\
\hline $\begin{array}{l}\text { Higher education } \\
\quad \text { Retirement dummies }\end{array}$ & 0.19 & 4.58 & 0.23 & 5.18 & -0.06 & -1.47 & -0.04 & -0.99 \\
\hline Retiring (self defined) between $t-1$ and $t$ & -0.12 & -1.40 & -0.12 & -1.41 & 0.14 & 1.78 & 0.14 & 1.78 \\
\hline Retirin & -0.04 & -0.48 & -0.04 & -0.52 & 0.15 & 2.15 & 0.15 & 2.2 \\
\hline Retirin & -0.10 & -1.39 & -0.10 & -1.42 & -0.10 & -1.48 & -0.10 & -1.51 \\
\hline $\begin{array}{l}\text { Turning } 65 \text { in } \mathrm{t} \\
\text { Mandatory retirement for lower }\end{array}$ & -0.27 & -4.74 & -0.09 & -1.10 & -0.13 & -2.66 & 0.04 & 0.48 \\
\hline $\begin{array}{l}\text { vocational education } \\
\text { Mandatory retirement for intermediate }\end{array}$ & & & 0.11 & 0.71 & & & -0.11 & -0.79 \\
\hline $\begin{array}{l}\text { vocational education } \\
\text { Mandatory retirement for higher }\end{array}$ & & & -0.48 & -3.55 & & & -0.48 & -3.73 \\
\hline $\begin{array}{l}\text { education } \\
\quad \text { Shocks and incentives }\end{array}$ & & & -0.54 & -3.14 & & & -0.29 & -1.78 \\
\hline Labor market sh & -0.36 & -2.22 & -0.36 & -2.23 & 0.03 & 0.22 & 0.03 & 0.21 \\
\hline Becomes & 0.06 & 0.41 & 0.07 & 0.44 & 0.44 & 3.16 & 0.45 & 3.22 \\
\hline Gets mar & -0.03 & -0.09 & -0.03 & -0.08 & -0.36 & -1.15 & -0.36 & -1.16 \\
\hline Family gets bigger between $\mathrm{t}-\mathrm{l}$ and $\mathrm{t}$ & 0.01 & 0.05 & 0.00 & 0.03 & 0.21 & 1.49 & 0.22 & 1.51 \\
\hline Family gets smaller between $\mathrm{t}-1$ and $\mathrm{t}$ & 0.09 & 1.47 & 0.09 & 1.46 & -0.03 & -0.56 & -0.04 & -0.60 \\
\hline $\begin{array}{l}\text { First diff. of the PDV of earnings } / 10^{5} \\
\text { Potentially endogenous variables }\end{array}$ & 0.66 & 2.16 & 0.67 & 2.18 & & & & \\
\hline Mean family size & 0.14 & 2.89 & 0.14 & 2.89 & 0.12 & 2.62 & 0.13 & 2.68 \\
\hline $\begin{array}{c}\text { Mean of the first diff. of the PDV } / 10^{5} \\
\text { Ancillary statistics }\end{array}$ & 0.23 & 0.52 & 0.19 & 0.42 & & & & \\
\hline$m 1$ & -1.79 & -21.43 & -1.79 & -21.30 & -1.60 & -21.36 & -1.59 & -21.24 \\
\hline$m 2$ & -0.79 & -9.74 & -0.78 & -9.59 & -0.62 & -8.52 & -0.61 & -8.40 \\
\hline$m 3$ & 1.36 & 16.60 & 1.37 & 16.72 & 0.99 & 13.63 & 1.00 & 13.74 \\
\hline$m 4$ & 2.56 & 26.96 & 2.57 & 27.05 & 1.89 & 25.00 & 1.90 & 25.09 \\
\hline$\sigma^{2} \alpha$ & 0.22 & 1.37 & 0.21 & 1.33 & 0.14 & 0.90 & 0.14 & 0.90 \\
\hline $\begin{array}{l}\text { Log likelihood } \\
\text { Observations }\end{array}$ & & 331 & 994 & & & & & \\
\hline
\end{tabular}

Explanatory note: Expectations in the left panel are expressed in t, and in the panel on the right in t-1 (and subtracted from realizations in t). Reference cases : Year 1997, Elementary education. 
invariant characteristics such as attitude toward the future, that could well be positively and significantly correlated to larger family sizes. Including (non-capital) income as a regressor did not improve the results: the relative coefficient was not significant and is not present in this analysis.

\subsection{Gap between expectations and realizations}

The panel on the right of Table 4 reports the results for the model in which the difference between expectations in $t-1$ and realizations in $t$ is the dependent variable. It is organized like the panel with the expectations model results. Including the present value (PDV) of future earnings resulted in a coefficient that was not significant. We have estimated different specifications of the model, and in none the removal of this variable affected the results significantly. Therefore we decided to present two specifications that do not include the PDV variable. Before describing the main results, it is necessary to explain how the estimates should be interpreted. A positive sign is associated with higher values of the dependent variable. When the dependent variable increases this means that expectations exceed realizations: individuals are overly optimistic. When the dependent variable is lower it means that realizations exceed expectations: the respondent is overly pessimistic.

As in the left panel, again in Models 3 and 4 (which we describe together) time effects are also generally significant. Among the taste shifters, households with smaller family size are more pessimistic than they should be. None of the educational levels is significant.

The introduction of the interaction between mandatory retirement and the different education levels highlights the main finding of this study. When estimating the model without these interactions, again the coefficient relative to age 65 confirmed a significant overly pessimistic attitude of respondents in general. The interaction with education allows the identification of which groups are more inclined to underestimate the development of their finances. When individuals turn 65, the coefficients for intermediate education and higher education are negative and significantly different from zero. Hence higher-educated respondents are overly pessimistic when they become eligible for AOW. This means that they report lower expectations at age 64, but the year after, when they are 65, they state a better than expected evolution of their financial situation. Again this finding is in line with the descriptive analysis (see Figure 2), and with the findings of Ameriks, Caplin, and Leahy (2002a). In this sense, we intend the rational expectations hypothesis as 
questionable, because we look at the capacity of individuals to anticipate future events, and their systematic failure.

The dummies that identify changes of status are generally not significantly different from zero, with the exception of those experiencing widowhood or divorce. This indicates that a failure to state expectations that will comply with realizations does not depend only on labor-market-related shocks; nor on the occurrence of unexpected changes concerning family size. This is plausible since such shocks may well be anticipated (we cannot test for this). The coefficient associated with those becoming single (because of divorce or widowhood) is significant. This indicates that those experiencing such an event had been too optimistic. In short, after divorce or widowhood, individuals report realizations that are lower than the expectations reported before the occurrence of such event, as may be expected. Again, family size, as a time-invariant potentially endogenous covariate, is positive and significant. This indicates that those unobservables that make one choose to have a larger family are also associated with overly optimistic responses.

A comparison of the two models reveals the following:

- Around ER and when individuals turn 65, i.e. when they expect an income drop, their expectations deteriorate. Their fears are unjustified in the sense that they do not come true. The year after, the realizations of the individual financial situation are better than expected. This is particularly evident for higher-educated individuals becoming eligible for the AOW

- Changes of status, such as stopping work or becoming sick do play a significant role in the evolution of expectations. On the other hand becoming single is significantly correlated with the gap with realizations. Their actual effect is consistent with their a priori expected effect.

\subsection{Decomposition}

Given the above analysis, we feel confident in using the estimation results of the models to perform some simulations. The aim is to decompose the observed drop in expectations of individuals eligible for old age pension as determined by two different effects. The first effect is determined by all individual characteristics, the second exclusively by eligibility for mandatory retirement $(e)$. In order to identify these two effects, an Oaxaca decomposition is computed. 
In order to isolate the effect of eligibility, which enters the model with some indicators $\left(d_{e}\right)$, the following steps are followed. First, the estimates in the left panel of Table 4 are used to predict the mean value of expectations $(y)$ for those who are not eligible $\left(E\left(y_{e=0} \mid d_{e}=0\right)\right)$, separately from those who are eligible $\left(E\left(y_{e=1} \mid d_{e}=1\right)\right)$. For this second group, which is aged 64 in $t-1$, a second prediction is computed, i.e. the same way as the previous one, but dropping the eligibility indicator $\left(E\left(y_{e=1} \mid d_{e}=0\right)\right)$.

In this way, the overall effect $E\left(y_{e=0} \mid d_{e}=0\right)-E\left(y_{e=1} \mid d_{e}=1\right)$ is decomposed into two effects:

$$
\underbrace{\left[E\left(y_{e=0} \mid d_{e}=0\right)-E\left(y_{e=1} \mid d_{e}=0\right)\right]}_{\text {characteristics }}-\underbrace{\left[E\left(y_{e=1} \mid d_{e}=1\right)-E\left(y_{e=1} \mid d_{e}=0\right)\right]}_{\text {eligibility }}
$$

where the second term of 2 identifies the effect of the eligibility indicators on average expectations, since these are the only parameters that differ between the two predicted values.

In the observed data, expectations drop at age 64 from approximately 2.83 to 2.63 . The result of the decomposition indicates that individual characteristics account for an average drop of 0.10 , while eligibility indicators account for the remaining drop of 0.9 . This means that $46 \%$ of the drop in expectations is attributable to an eligibility effect, while the remaining $54 \%$ may be attributed to all other remaining characteristics.

\section{Summary and Conclusions}

A drop in expectations about the future financial situation is observed at age 64 . Such an expected drop is in line with the standard life-cycle model hypothesis that predicts decumulation of wealth after retirement, but is not mirrored in the observed outcomes. Even after controlling for observable characteristics and for the residual lifetime resources available to individuals, the drop is still evident. This shows that individuals become overly pessimistic at the age of eligibility for old age pension. Furthermore, around the early retirement age, the gap between expectations and realizations increases. This study exploits the Social Economic Panel data to investigate whether individuals fear a shock in their finances around retirement and whether their 
fears are justified. Tracking individuals over time allows a direct comparison to be made between expectations about the next year and the realizations of the year after, following the methodology of Das, Dominitz, and van Soest (1999). Rational individuals, loosely speaking, should be able to predict with accuracy their future, if macro- or micro-shocks do not disturb their environment. This is directly tested in this study. Thanks to the panel nature of the data, several definitions of micro-shocks are introduced. This is a rarely used approach for studies on the evolution of short-run expectations around retirement ${ }^{18}$. Also several definitions of early retirement are introduced in order to detect the exact timing of individual early retirement. Two types of random effect panel data models are estimated, both for expectations and for the gap with realizations.

The empirical results can be summarized as follows:

- The covariates introduced produce, in general, plausible estimation results.

- Individuals do fear a shock in their financial situation, but their fears are, in general, unjustified. Such fears are mainly evident for-higher educated respondents

- Macro-shocks are a significant determinant of expectations, but, over the 10-year period of this analysis, they go in different directions.

- micro-shocks are also a significant component that explains part of the gap between expectations and realizations.

- The generosity of the pension system in the long run has a direct effect on the evolution of expectations.

- Decomposing the effect of all covariates on expectations attributes to eligibility for old age pension a large effect in determining the expectations drop at age 64 .

This means that individuals, around (mandatory) retirement age, are overly pessimistic and attach more weight to prospective bad events than to good events. This questions the adoption of the expected utility framework

\footnotetext{
${ }^{18}$ Disney and Tanner (1999) introduce micro-shocks in their analysis, but they investigate expected retirement age. Using only two waves, they cannot test for the systematic relation between these "shocks", expectations, and realizations, for all individuals.
} 
with rational expectations employed in the estimation of the (post-retirement part of the) life-cycle model. The results of this study are in line with several studies that make use of directly reported expectations and realizations. In particular the findings of Ameriks, Caplin, and Leahy (2002a), are confirmed here and reinforced by the use of the panel, the inclusion of an individual effect, the inclusion of different definitions of retirement status, and microshocks. The idea that individuals are surprised by the inadequacy of resources, and therefore need to decumulate their wealth, does not find direct support in this study. It seems plausible to conclude that it is eligibility per se that drives the drop in expectations and, therefore, the mismatch with realizations.

\section{References}

Alessie, R., And A. Kapteyn (2001): "Savings and pensions in the Netherlands," Ricerche Economiche, 1(55), 61-82.

Ameriks, J., A. Caplin, And J. Leahy (2002a): "Retirement Consumption: Insights from a Survey," NBER Working Papers, (8735).

(2002b): "Wealth Accumulation and Propensity to Plan," NBER Working Papers, (8920).

Banks, J., R. Blundell, and S. TAnner (1998): "Is there a retirement-savings puzzle?," American Economic Review, (88).

Chan, S., And A. H. Stevens (2001): "Retirement Incentive and Expectations," NBER Working Papers, (8082).

Coile, C., And J. Gruber (2000): "Social Security Incentives for Retirement," NBER Working Papers, 7651.

Das, M. (1998): "On Income Expectations and Other Subjective Data, A MicroEconometric Analysis," Ph.D. thesis, Tilburg University, Tilburg, The Netherlands.

Das, M., J. Dominitz, and A. van Soest (1999): "Comparing Predictions and Outcomes: Theory and Application to Income Changes," Journal of the American Statistical Association, 94, 75-85. 
Das, M., And A. van Soest (1997): "Expected and Realized Income Changes: Evidence from the Dutch Social Economic Panel," Journal of Economics Behavior and Organization, 32, 137-154.

(1999): "A Panel Data Model for Subjective Information on Household Income Growth," Journal of Economics Behavior and Organization, 40, 409426.

(2001): "Expected versus Realized Income Changes: a Test of the Rational Expectations Hypothesis," Working Paper.

Disney, R., And S. TAnneR (1999): "What can we Learn from Retirement Expectations Data," IFS working paper, W99-17.

Dominitz, J., C. F. Manski, And J. Heinz (2002): "Social Security Expectations and Retirement Savings Decisions," NBER Working Papers, (8718).

Gustman, A. L., and T. L. Steinmeier (2001): "Imperfect Knowledge Retirement and Savings," NBER Working Papers, (8046).

Hurd, M. D., And S. Rohwedder (2003): "The Retirement-Consumption Puzzle: Anticipated and Actual Declines in Spending at Retirement," NBER Working Papers, 9586.

Lindeboom, M. (1999): "Het Arbeidsmarktgedrag van Oudere Werknemers," VU Boekhandel Uitgeverij Amsterdam.

Lusardi, A. (2000): "Explaining Why So Many People Do Not Save," Working Paper University of Chicago, Harris School of Public Policy. 


\section{Appendices}

\section{A Expected versus realized wealth changes}

According to Das and van Soest (2001) if individuals are perfectly rational, they should report a location of their individual subjective distribution that coincides with the one relative to the distribution of the realization. As in Table 3, some insight could be gained by comparing predictions with selfreported outcomes. But such comparison is not straightforward, since there is no reason to expect that the distribution of expectations across the population is the same as the distribution of the actual variable. Even when realizations and predictions coincide, the two variable are not comparable. While the outcome is based on the distribution of the actual variable, expectations reflect some location of the individual subjective distribution (mode, mean, etc...). One could try to study such locations by considering different models which generate the best predictions of the prospective realizations. One could think of respondents minimizing a loss function. Respondents could, for instance, refer to the modal category or to some quantile of the subjective distribution. In the first case, when confronted with the five ordered categories of the question, respondents could report the mode of their subjective distribution. In the second they could instead report the median.

The data contain questions eliciting expectations of outcome $y=$ financial situation; where respondents may choose among ordered categories. Let $f(y \mid s)$ be the subjective probability density of outcome $y$, given information $s$. Respondents choose one of the $K$ categories $C_{1}, \ldots, C_{K}$ of the form $C_{k}=$ $\left(m_{k-1}, m_{k}\right]$, with $-\infty=m_{0}<m_{1}<\ldots<m_{k-1}<m_{K}=\infty$. The threshold values $m_{k}$ are subjectively determined, and ordered models may be used to estimate their values. The answer to the expectation question is denoted by $p$. The minimization of some loss function will return $p$ (see formula 3). If the respondents answer the question having in mind the most likely outcome, they will report the mode of their subjective distribution. This means that they report the category $p=\arg \max _{k} P\left\{y \in C_{k} \mid s\right\}$. This corresponds to minimizing, with respect to $k$, the expected loss function: $E\left\{1\left(y \notin C_{k}\right) \mid s\right\}$. Here the behavior of an individual forming some point expectations $p^{*}$, and choosing the category $p$ that contains $p^{*}$, is treated. The general form of the problem is minimizing the expected loss for some loss function $L$ : 


$$
\begin{gathered}
p^{*}=\underset{\pi}{\arg \min } \int_{-\infty}^{\infty} L(y-\pi) f(y \mid s) d y \\
p=k \text { iff } p^{*} \in C_{k} .
\end{gathered}
$$

If respondents interpret the question as eliciting the median of $f(y \mid s)$, the relative loss function will be $L(u)=|u|$, while for the category containing the mean the loss function will be $L(u)=u^{2}$.

If individual expectations are rational, the categorized answer to the question about expectations and to the question about realizations should mirror a location from the same distribution. This location could be, for instance, the mode, the median, or the mean of such individual distribution. By comparing expectations and outcomes, the following tests are performed to show that what individuals report is not one of those locations, and this questions the validity of the rational expectations hypothesis.

\section{A.0.1 Modal category}

Following Das and van Soest (1997), we formalize the modal category assumption for individual $i$, given the available information $x_{i}$, as:

$$
P\left\{c_{i}=k \mid x_{i}, p_{i}=k\right\} \geq P\left\{c_{i}=j \mid x_{i}, p_{i}=k\right\}, \quad j=1, \ldots, K,
$$

where $c_{i}$ is the realized category and $k$ is the predicted category. For those individuals with $p_{i}=k$, most outcomes will be located in category $k$. Realizations, in the best-case scenario, are based upon drawings from the same distribution leading to probabilities 4 . We can use observations of $c_{i}$ to see whether expression 4 holds. Define for notational convenience $P_{j} \equiv$ $P\left\{c_{i}=j \mid x_{i}, p_{i}=k\right\}$. Let $\hat{P}_{j}$ be the sample equivalent of $P_{j}{ }^{19}$. Under the hypothesis of the independence of realizations, frequencies of financial situation can be used to estimate the probabilities in 4 . Assuming $x_{i}=$ year of observation Table 3A1 reports the frequencies. Table 3A1 shows that only for the case $k=3$ could the modal category assumption be used as a model generating expectations. For $k=1$, for instance, this is only true in years 1995-1996 and 1996-1997. Globally only 14 cases out of 40 behave according to the modal category assumption,which suggests its irrelevance ${ }^{20}$.

\footnotetext{
${ }^{19}$ That is the number of observations with $c=j$ and $p_{i}=k$ and the given value of $x_{i}$.

${ }^{20}$ We have also estimated Table $3 \mathrm{~A} 1$ conditional on several covariates of $x_{i}$, such as gender and education. The results are confirmed.
} 


\section{A.0.2 Median Category}

If the survey responses correspond to a category that contains a point prediction that minimizes a loss function, it is natural to interpret $p_{i}$ as containing the $\alpha$-quantile of the respondent's subjective distribution of $y_{i}$. For $\alpha=0.5$, the category is the one containing the median. If $p_{i}^{*}$ is the $\alpha$-quantile (corresponding, for convenience, to the cumulative probability $\alpha$ ) then in the best case scenario it must be:

$$
P\left\{y_{i}-p_{i}^{*} \leq 0 \mid x_{i}\right\}=\alpha .
$$

Since we observe the category $c_{i}$, we focus on the case with $c_{i}=k$. Then:

$$
P\left\{c_{i} \leq k-1 \mid s_{i}, p_{i}=k\right\}<\alpha \leq P\left\{c_{i} \leq k \mid s_{i}, p_{i}=k\right\}
$$

that implies the following inequalities: 


\begin{tabular}{|c|c|c|c|c|c|c|c|}
\hline \multicolumn{8}{|c|}{ Table 3A1: Estimates of $P\left\{c_{i}=c \mid p_{i}=k\right\}$} \\
\hline & & $\mathrm{c}=1$ & $\mathrm{c}=2$ & $\mathrm{c}=3$ & $\mathrm{c}=4$ & $\mathrm{c}=5$ & Obs \\
\hline \multirow{8}{*}{$\begin{array}{l}\mathrm{k}=1 \\
\text { strong } \\
\text { decrease }\end{array}$} & '90-'91 & $18 \%$ & $24 \%$ & $47 \%$ & $6 \%$ & $6 \%$ & 17 \\
\hline & '91 - '92 & $32 \%$ & $23 \%$ & $42 \%$ & $3 \%$ & $0 \%$ & 31 \\
\hline & '92 - '93 & $32 \%$ & $19 \%$ & $35 \%$ & $13 \%$ & $0 \%$ & 31 \\
\hline & '93 - '94 & $27 \%$ & $34 \%$ & $32 \%$ & $7 \%$ & $0 \%$ & 44 \\
\hline & '94 - '95 & $35 \%$ & $13 \%$ & $39 \%$ & $11 \%$ & $2 \%$ & 84 \\
\hline & '95 - '96 & $40 \%$ & $28 \%$ & $28 \%$ & $2 \%$ & $2 \%$ & 53 \\
\hline & '96 - '97 & $40 \%$ & $27 \%$ & $22 \%$ & $11 \%$ & $0 \%$ & 73 \\
\hline & '97 - '98 & $35 \%$ & $20 \%$ & $37 \%$ & $0 \%$ & $8 \%$ & 65 \\
\hline \multirow{8}{*}{$\begin{array}{l}\mathrm{k}=2 \\
\text { decrease }\end{array}$} & $' 90-' 91$ & $16 \%$ & $33 \%$ & $48 \%$ & $3 \%$ & $0 \%$ & 132 \\
\hline & '91 - '92 & $12 \%$ & $35 \%$ & $46 \%$ & $7 \%$ & $1 \%$ & 183 \\
\hline & '92 - '93 & $8 \%$ & $32 \%$ & $49 \%$ & $9 \%$ & $2 \%$ & 180 \\
\hline & '93 - '94 & $5 \%$ & $43 \%$ & $42 \%$ & $7 \%$ & $2 \%$ & 204 \\
\hline & '94 - '95 & $10 \%$ & $32 \%$ & $47 \%$ & $9 \%$ & $2 \%$ & 363 \\
\hline & '95 - '96 & $10 \%$ & $33 \%$ & $48 \%$ & $7 \%$ & $1 \%$ & 279 \\
\hline & '96 - '97 & $8 \%$ & $32 \%$ & $50 \%$ & $9 \%$ & $1 \%$ & 312 \\
\hline & '97 - '98 & $8 \%$ & $24 \%$ & $51 \%$ & $16 \%$ & $1 \%$ & 228 \\
\hline \multirow{8}{*}{$\begin{array}{l}\mathrm{k}=3 \\
\text { no } \\
\text { change }\end{array}$} & '90 - '91 & $3 \%$ & $12 \%$ & $70 \%$ & $13 \%$ & $2 \%$ & 667 \\
\hline & '91 - '92 & $3 \%$ & $16 \%$ & $66 \%$ & $13 \%$ & $2 \%$ & 581 \\
\hline & '92 - '93 & $3 \%$ & $19 \%$ & $66 \%$ & $10 \%$ & $1 \%$ & 616 \\
\hline & '93 - '94 & $4 \%$ & $18 \%$ & $66 \%$ & $10 \%$ & $1 \%$ & 607 \\
\hline & '94 - '95 & $3 \%$ & $14 \%$ & $70 \%$ & $12 \%$ & $1 \%$ & 1031 \\
\hline & '95 - '96 & $5 \%$ & $18 \%$ & $67 \%$ & $9 \%$ & $1 \%$ & 1172 \\
\hline & '96 - '97 & $3 \%$ & $14 \%$ & $67 \%$ & $14 \%$ & $2 \%$ & 1098 \\
\hline & '97 - '98 & $3 \%$ & $12 \%$ & $65 \%$ & $18 \%$ & $2 \%$ & 1145 \\
\hline \multirow{8}{*}{$\begin{array}{l}\mathrm{k}=4 \\
\text { increase }\end{array}$} & '90 - '91 & $2 \%$ & $7 \%$ & $54 \%$ & $28 \%$ & $8 \%$ & 95 \\
\hline & '91 - '92 & $5 \%$ & $15 \%$ & $46 \%$ & $24 \%$ & $10 \%$ & 100 \\
\hline & '92 - '93 & $0 \%$ & $6 \%$ & $44 \%$ & $41 \%$ & $9 \%$ & 94 \\
\hline & '93 - '94 & $7 \%$ & $7 \%$ & $55 \%$ & $26 \%$ & $5 \%$ & 76 \\
\hline & '94 - '95 & $3 \%$ & $27 \%$ & $38 \%$ & $23 \%$ & $9 \%$ & 115 \\
\hline & '95 - '96 & $3 \%$ & $10 \%$ & $41 \%$ & $40 \%$ & $6 \%$ & 144 \\
\hline & '96 - '97 & $5 \%$ & $5 \%$ & $48 \%$ & $33 \%$ & $10 \%$ & 147 \\
\hline & '97 - '98 & $1 \%$ & $10 \%$ & $36 \%$ & $50 \%$ & $3 \%$ & 176 \\
\hline \multirow{8}{*}{$\begin{array}{l}\mathrm{k}=5 \\
\text { strong } \\
\text { increase }\end{array}$} & '90 - '91 & $0 \%$ & $0 \%$ & $60 \%$ & $20 \%$ & $20 \%$ & 5 \\
\hline & '91 - '92 & $0 \%$ & $14 \%$ & $43 \%$ & $0 \%$ & $43 \%$ & 7 \\
\hline & '92 - '93 & $0 \%$ & $0 \%$ & $38 \%$ & $50 \%$ & $13 \%$ & 8 \\
\hline & '93 - '94 & $0 \%$ & $0 \%$ & $33 \%$ & $33 \%$ & $33 \%$ & 3 \\
\hline & '94 - '95 & $13 \%$ & $13 \%$ & $33 \%$ & $13 \%$ & $27 \%$ & 15 \\
\hline & '95 - '96 & $11 \%$ & $6 \%$ & $950 \%$ & $33 \%$ & $0 \%$ & 18 \\
\hline & '96 - '97 & $0 \%$ & $12 \%$ & $18 \%$ & $59 \%$ & $12 \%$ & 17 \\
\hline & '97 - '98 & $0 \%$ & $0 \%$ & $42 \%$ & $17 \%$ & $42 \%$ & 12 \\
\hline
\end{tabular}


Explanatory note: $k=$ predicted category; $c=$ realized category. Respondents are selected when participating for two consecutive years in the survey.

Source SEP: own computations. 


$$
\begin{aligned}
& P\left\{c_{i}>k \mid x_{i}, p_{i}=k\right\} \leq 1-\alpha \\
& P\left\{c_{i}<k \mid x_{i}, p_{i}=k\right\}<\alpha .
\end{aligned}
$$

To fit in the best-case scenario the, $\alpha$-quantile of $c_{i}$ must fall in category $k$, given that $p_{i}=k$; with no more than $100 \alpha \%$ of realized values in the lower categories, and no more than $100(1-\alpha) \%$ in higher categories. A test for 5 and 6 is reported in Table 3A2 using the data of table 3A1 and is based upon:

$$
\sqrt{n}\left(\sum_{j=k+1}^{K} \hat{P}_{j}-\sum_{j=k+1}^{K} P_{j}\right) \underset{\imath}{\rightarrow} N\left(0,\left(1-\sum_{j=k+1}^{K} P_{j}\right) * \sum_{j=k+1}^{K} P_{j}\right)
$$

where $n$ is the number of observations, and $x_{i}$ is only composed by year of observation. In the table, the value of $\alpha=0.5$ should be included in the confidence intervals in order to conclude that individuals are reporting a median as a point expectation.

This test uses the ordering of the categories. This suggests that the assumptions required for the modal category case were less stringent. For the case of $\alpha=0.5$, we see that 5 and 6 for all $k$ do not imply that 4 holds for all $k$ and $j$, and vice versa. It is true though that, for the extreme values of the $k$ categories, the inequalities 5 and 6 will hold ${ }^{21}$. Such a test imposes the condition that an absolute majority should fall into a certain category, rather than a relative majority as in the modal case. In this sense, the median category assumption is more restrictive and it does not come as a surprise that the results are poor in terms of predictive capacity.

\section{A.0.3 Mean category}

When the loss function is $L(u)=u^{2}$, then $p_{i}$ reflects the category containing the mean. To test this implication, we need the rich data that, in the SEP, approximate the concept of $y_{i}$, rather than the ordered category $c_{i}$. We use

\footnotetext{
${ }^{21}$ Namely, for $k=1$, i.e. the first category, (5) implies (4), while for the last category $k=K=5,(6)$ implies (4).
} 
liquid wealth as a proxy for household financial condition, as mentioned in the question eliciting $c_{i}$ (see Section 3.2).

In this case, the answer $p_{i}$ is the category containing $E\left\{y_{i} \mid x_{i}\right\}$. When $p_{i}=k$, then $p^{*}$ will fall within two adjacent thresholds $\left(m_{k-1}\right.$ and $\left.m_{k 1}\right)$. That is:

$$
E\left\{y_{i} \mid x_{i}, p_{i}=k\right\} \in\left(m_{k-1, i}, m_{k, i}\right] .
$$

Given the presence of outliers in the distribution of wealth changes the first and the last $5 \%$ percentile were omitted in the computation of Table $3 \mathrm{~A} 3$. 


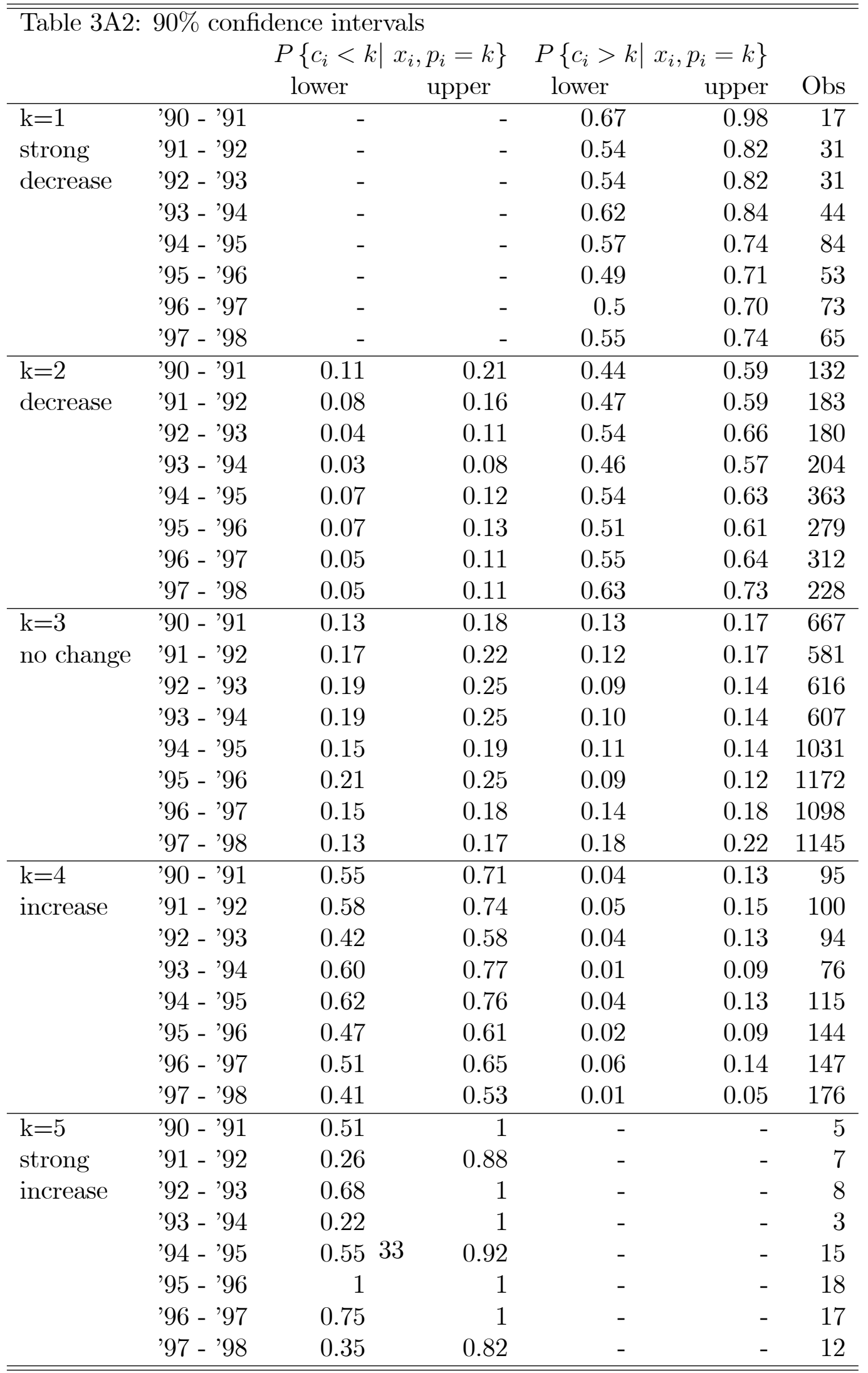


Explanatory note: Predicted category $=k . c=$ realized category; $x=$ year. Source: SEP, own computations 
In addition, in this case, $x_{i}$ is defined by gender to keep the amount of observations higher in any cell.

In Table 3A3 standard deviation increases with $k$ in the case of females, but not the sample means, as we would expect. For males instead the sample means are conveniently ordered. This table also produces mixed results. This could depend on the definition of $y$ that we adopt.

Overall, none of the three hypotheses tested produced conclusive results, probably indicating that individual may actually be minimizing asymmetric loss functions that attach more weight to lower expectations categories. More simply, the individual distribution of expectations and realization do not coincide, as the rational expectations hypothesis would suggest. Das (1998), who has similar results, using income data, is able to test this implication directly. He finds that asymmetric results are plausible and that individual attach more weight to perspective worse events. The erratic nature of observed wealth changes makes this test unfeasible in our case, since it is again based on the (cumulative) distribution of $y_{i}=$ liquid wealth.

\begin{tabular}{crrr}
\hline \multicolumn{3}{c}{ Table 3A3: Wealth changes per expectation category } \\
& $k$ & liquid wealth (standard deviations) & Obs \\
\hline male & 1 & $-1884.551(41247.86)$ & 312 \\
& 2 & $-929.1975(31921.63)$ & 930 \\
& 3 & $1430.206(40940.27)$ & 3557 \\
& 4 & $4620.814(42084.57)$ & 852 \\
& 5 & $24031.61(88995.39)$ & 160 \\
\hline female & 1 & $123.2286(26948.55)$ & 321 \\
& 2 & $-510.8509(27234.47)$ & 986 \\
3 & $1366.885(38709.88)$ & 3538 \\
4 & $4521.063(44765.27)$ & 692 \\
& 5 & $20587.99(92683.27)$ & 101 \\
\hline
\end{tabular}

Explanatory note: Respondents are selected when participating for three consecutive years in the survey. Predicted category $=k . k=1$ is a big decrease; $k=2$ is a decrease; $k=3$ is equal; $k=4$ is an increase; $k=5$ is a big increase. Source: SEP, own computations 


\section{B Imputation of PDV variable}

The present discounted value of future incomes and benefits is included as an explanatory variable in the ordered probit model described in Section 4. This variable is derived under several assumptions concerning both the behavior of individuals towards the pension system and the ev5olution of their income profile till age 69 .

\section{B.1 Opting out at Early Retirement}

Previous research demonstrates that the institutional and financial incentives related to ER are so favorable in the Netherlands that the vast majority of individuals who are eligible for ER do actually opt out as soon as they become eligible (see, e.g., Lindeboom (1999)). Unfortunately, in the SEP, the ER entitlement age is not observed. That is why we use an auxiliary data set, the CERRA, to estimate the probability distribution of eligibility.

A logit model and an ordered logit model are estimated for the availability of an ER scheme and the age of eligibility given entitlement, respectively (see Table 3B1). As explanatory variables, we include some individual background variables, a dummy variable for public sector and experience. The choice of the RHS variables is motivated by convenience and based on the consideration of the most common entitlement rules to ER schemes. Next, the parameters' estimates are used to compute the probability distribution of the expected ER age for individuals in the SEP. This distribution is used to compute part of the present discounted value of those who work up to the age of ER eligibility, that (early) retire at that age, and eventually receive ER benefit till age 64 and old age pension plus occupational pension from age 65 to 69 . Hence, knowing the probability of retirement at a certain age identifies the (fraction of) the future income that will be used for the computation of the occupational pension after age $65^{22}$. We report the model results for eligibility in Table 3B1 ${ }^{23}$.

\footnotetext{
${ }^{22}$ Another option could be to predict only labor earnings. This, however, would be problematic for those who have already partially entered an ER scheme and have a low labor income and a positive pension income.

${ }^{23}$ 'Eligibility' is derived from the answer to the question : "Does the company you work for now have an ER scheme?". 'Eligibility age' is derived from the question: "What is the minimum age to enter the ER scheme offered by your company?"
} 


\begin{tabular}{|c|c|c|}
\hline \multicolumn{3}{|c|}{ Table 3B1 . Eligibility Model } \\
\hline & Eligibility & Eligibility Age \\
\hline \multirow[t]{2}{*}{ Age } & 0.060 & 0.031 \\
\hline & $(2.26)^{* *}$ & $(1.61)^{*}$ \\
\hline \multirow[t]{2}{*}{ Experience } & -0.060 & 0.005 \\
\hline & $(8.28)^{* * *}$ & $(0.90)$ \\
\hline \multirow[t]{2}{*}{ Married } & 0.158 & -0.113 \\
\hline & $(0.33)$ & $(0.44)$ \\
\hline \multirow[t]{2}{*}{ Divorced } & -0.071 & -0.080 \\
\hline & $(0.13)$ & $(0.25)$ \\
\hline \multirow[t]{2}{*}{ Single } & 0.660 & -0.195 \\
\hline & $(1.06)$ & $(0.46)$ \\
\hline \multirow[t]{2}{*}{ Sector } & & 2.271 \\
\hline & & $(17.02)^{* * *}$ \\
\hline \multirow[t]{2}{*}{ Constant } & -3.527 & \\
\hline & $(2.31)^{* *}$ & \\
\hline Observations & 987 & 1240 \\
\hline Pseudo R2 & 0.07 & 0.09 \\
\hline Log likelihood & -502.80 & -1742.44 \\
\hline
\end{tabular}

Explanatory note: The reference case for marital status is widow; for sector, it is private sector. T-values within brackets.

Source: CERRA, own computations.

\section{B.1.1 Income profiles}

Income profiles are generated according to the following auto-regressive fixedeffect panel data model ${ }^{24}$. The within-estimator for the fixed effect model is derived from

$$
y_{i t}=\alpha+x_{i t} \beta+\nu_{i}+\varepsilon_{i t} \quad i=1, \ldots, N ; \quad t=1, \ldots, T_{i},
$$

where $\varepsilon_{i t}=\rho \varepsilon_{i, t-1}+\eta_{i t}$, and $|\rho|<1$ and $\eta_{i t}$ is iid with zero mean and variance $\sigma_{n}^{2}$, while $\nu_{i}$ are fixed parameters that can be correlated to $x_{i t}$ if those vary over time.

\footnotetext{
${ }^{24}$ The model is specified only for predictions, and is not meant to be an income model with causality relations.
} 
Table 3B2 contains the results of the fixed-effect model for total earnings in $t$ and $t-1^{25}$.

\begin{tabular}{lll}
\hline \hline \multicolumn{2}{l}{ Table 3B2. Non-Capital Income Model. } & \\
& $\begin{array}{l}\text { Total Income in t } \\
\text { Non-capital income in t }\end{array}$ & Total Income in t-1 \\
& $-(2.045)^{* * *}$ & \\
Age in t & $1,599.866$ & \\
& $(4.83)^{* * *}$ & \\
Age square in t & 6.050 & \\
& $(1.60)$ & -0.094 \\
Non-capital income in t-1 & & $-(6.39)^{* * *}$ \\
& & -684.795 \\
Age in t-1 & & $(2.71)^{* * *}$ \\
& & 30.826 \\
Age square in t-1 & & $(8.36)^{* * *}$ \\
& & $-17,536.867$ \\
Constant & $-67,311.886$ & $-(5.01)^{* * *}$ \\
& $-(8.97)^{* * *}$ & 5202 \\
Observations & 4836 & 1420 \\
Number of groups & 1341 & -57789.98 \\
Log likelihood & -53757.26 & 0.31 \\
Ro AR & 0.16 & \\
\hline \hline
\end{tabular}

Explanatory note: t-values within brackets.

Source: SEP, own computations.

\section{B.2 Implementation of ER age in the present discounted value}

As stated above, in the SEP, we do not observe the eligibility age of ER schemes in the private sector but the probability distribution of it. We may observe an individual working at age 57 . For this individual, we have imputed a probability distribution for $e$ (year of eligibility) in the SEP. This associates

\footnotetext{
${ }^{25}$ This is done to allow the computation, for each panel wave, of the first difference of the PDV which is used in the estimation.
} 
a probability of becoming eligible to any age between 55 and 64 . We will treat this individual as if he were not eligible at age 55 and 56 . So the probability of becoming eligible at age 57 will be conditioned on the sum of the probabilities at age 55 and 56. In the remainder of this Appendix, we will show how to integrate out of the pension formula the unknown ER eligibility age using its distribution. Define the random variable $e_{t}$ as the year in which someone becomes eligible to ER, $y$ as non-capital income, and $l$ as labor participation.

The present discountedvalue (PDV) of continued work will result from the sum of the PDV of non-capital income till age $64\left(y_{t}\right)$, as derived in Table $3 \mathrm{~B} 2$, plus the PDV of pension $(P)$. This last item, the pension benefit from age 65 on, is the sum of old age pension $(A O W)$ plus occupational pension. Eligibility probabilities only matter for the computation of the occupational pension (that depends on experience (ten), last salary $(w)$, and the franchise $(f r a))$. This means that, for any individual, the following will hold:

$$
P D V\left(y_{t}+P \mid l_{0}=1\right)=
$$

$\sum_{t=\tau}^{R} y_{t}+\sum_{t=R}^{T} A O W+\operatorname{Pr}\left(e_{t} \leq t \mid e_{t}>\tau\right) *\left[\min (40\right.$, ten $+t-\tau) * 1,75 \% *\left(w_{t}-\right.$ fra $\left.)\right]$

where $R$ =year when old age pension begins, $\tau$ is the current period. Evidently both the franchise and the AOW are kept to the current level and the discount rate is 1 (does not appear in the formula). 